\title{
In-Situ Synthesis and Property Evaluation of High-Density Polyethylene Reinforced Groundnut Shell Particulate Composite
}

\author{
Adetayo Abdulmumin Adebisi, Tajudeen Mojisola, Umar Shehu, Muhammed Sani Adam and \\ Yusuf Abdulaziz
}

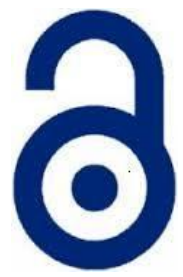

Received: 09 March 2021

Accepted: 24 July 2021

Published:01 October 2021

Publisher: Deer Hill Publications

(c) 2021 The Author(s)

Creative Commons: CC BY 4.0

\begin{abstract}
In-situ synthesis of high-density polyethylene (HDPE) reinforced groundnut shell particulate (GSP) composite with treated CSP within the range of 10-30 wt\% at $10 \mathrm{wt} \%$ has been achieved. The adopted technique used in the production of the composite is melt mixing and compounding using two roll mills with a compression moulding machine. Properties such as hardness, tensile strength, impact energy and water absorption analysis were examined. The result revealed that addition of GSP increases the hardness value from 22.3 to $87 \mathrm{Hv}$. However, the tensile strength progressively decreased as the GSP increases in the HDPE. This trend arises due to the interaction between neighbouring reinforced particulate which appears to influence the matrix flow, thereby inducing embrittlement of the polymer matrix. It was also observed that water absorption rate steadily increased with an increase in the exposure time and the absorbed amount of water increases by increasing the wt $\%$ of the GSP. Analysing the obtained results, it was concluded that there were improvements in the hardness, tensile strength, impact energy and water absorption properties of the HDPE-GSP polymer composite when compared to unreinforced HDPE. On these premises, GSP was found as a promising reinforcement which can positively influence the HDPE properties of modern composites.
\end{abstract}

Keywords: High density polyethylene (HDPE), Groundnut shell particulate (GSP), Melt mixing, Compounding, Compression moulding machine.

\section{INTRODUCTION}

In recent years, natural fibre reinforced polymers have started emerging as new eco-friendly polymeric composite materials with superior engineering properties such as low density, acceptable specific strength and specific stiffness, reduced tool wear and non-abrasiveness [1]. They are also commercially cost effective, environmentally friendly, reduce dependence on non-renewable sources, reduce pollutant and greenhouse gas emissions and offer enhanced energy recovery. The easy availability and presence of cellulose imparts good mechanical properties to natural fibres which makes it viable for promoting natural fibre reinforced polymer composites. The presence of cellulose makes natural fibres hydrophilic, however, the adhesion with hydrophobic polymer matrix reduces load transfer from matrix to fibre in the composite thereby limiting the mechanical properties [2]. This limitation can be overcome by improving the fibre-matrix interfacial adhesion through surface modification of the natural fibre through chemical or physical treatment, use of coupling agent and chemically functionalized matrix.

These naturally occurring fibres have been extensively used as reinforcements in polymer matrices as compared to the non-degradable synthetic fibres such as carbon, glass or aramid. They have shown to be invaluable when used as reinforcing filler in the polymer matrix. Several natural fibres have been investigated and they include coir fibre [3], wood fibre [4], rice straw fibre [5], sisal fibre [6], hemp fibre [7], kenaf fibre [8] and chitosan [9]. Groundnut shell is a waste product obtained after the removal of groundnut seed from its pod, and there has not been substantial demand for the utilization of groundnut shell for economic and commercial purpose. It is one of such natural agro waste filler with potential to be used as reinforcement as it contains cellulose, hemicellulose and lignin. It is a valuable product in composite production process due to its high availability in Northern Nigeria and scarce interest in other

A. A. Adebisi, A. A. ${ }^{1,2}$ 区, Mojisola, T. ${ }^{2}$, Shehu, U1, Adam, S. M. ${ }^{2}$ and Abdulaziz, $Y^{1}$

'Department of Metallurgical and Materials Engineering, Ahmadu Bello University, Zaria, Nigeria

${ }^{2}$ Metallurgical and Materials Engineering Department, Air Force Institute of Technology, Kaduna, Nigeria

E-mail: aaadebisi@abu.edu.ng

a.adebisi@afit.edu.ng

References: Adebisi et al. (2021). In-situ Synthesis and Property Evaluation of High-Density Polyethylene Reinforced Groundnut Shell Particulate Composite. International Journal of Engineering Materials and Manufacture, 6(4), 305-311. 
industrial sectors [10]. On the other hand, high density polyethylene (HDPE) is one of the important grades of polyethylene (PE) that exhibits excellent properties such as chemical stability barrier, good thermal resistance and mechanical strength. These properties make HDPE a versatile material in the manufacture of many products and packaging such as milk jugs, detergent bottles, margarine tubes, and garbage containers [11].

In their study, Jacob et al., [12] reported the dynamic mechanical characterization of groundnut shell powder filled recycled high-density polyethylene composite. The experiments were conducted using treated and untreated groundnut shell powder. Dynamic mechanical properties such as storage modulus, loss modulus and damping parameter were found to improve with the incorporation of treated groundnut shell powder. The inherent properties of the groundnut shell powder have made it a good reinforcing material in the development of composite. Similarly, Olaitan et al., [13] investigated the comparative assessment of mechanical properties of groundnut shell and rice husk reinforced epoxy composite. This investigation considered two different reinforcement groundnut shell and rice husk. After comparing the mechanical properties of the two reinforcements, it was revealed that groundnut shell epoxy composite displayed higher mechanical properties as compared to the rice husk epoxy composite. Musa et al., [14] studied on the mechanical and morphological properties of high-density polyethylene (HDPE) leather waste composites. The study shows that without additives, HDPE/Chrome tanned composites had higher modulus with lower tensile strength and impact strength. Moreover, Souza et al., [15] investigated on the mechanical properties of HDPE/textile fibres composites. The investigation result shows that the addition of modified fibres from industrial residue to HDPE improve the tensile strength and modulus which means there is an improvement in the mechanical property. Based on the studies highlighted, groundnut shell and HDPE have potential to be processed for use as composite material. However, there is limited or no information available in the literatures on the study. Therefore, this study aims to investigate the mechanical and water absorption properties of high-density polyethylene reinforced groundnut shell particulate composite using compression moulding technique.

\section{MATERIALS AND METHODS}

\subsection{Materials}

The HDPE was obtained from the Department of Metallurgical and Materials Engineering, Ahmadu Bello University, Zaria and the groundnut shells were locally sourced from Dawanau market in Kano state, Nigeria. The shells were washed thoroughly to remove dirt and dried to enable easy crushing and grinding into smaller sizes using shredding machine and a sieve of size less than $<0.3 \mathrm{~mm}$ (300 micrometres) was used. The sieved groundnut shell was then immersed and treated in $5 \% \mathrm{NaOH}$ for 1, 2, 3 hours with continuous stirring after which the solution was decanted off, washed several times with distilled water until the solution becomes neutral. The ground nut shell was then dried in an oven at a temperature of 105 degrees for 6 hours.

\subsection{Method}

\subsubsection{Composite Preparation}

The mould used for the preparation of the composite is an iron mould with a dimension of $100 \times 100 \times 30 \mathrm{~mm}$. An equivalent volume of HDPE was weighed using analytical weighing balance for each sample size. The weight percentage of $0-30(0,10,20$, and 30$) w t \%$ of groundnut shell were calculated from the weight of the control sample of HDPE, weighed and tight up in different nylons for production of the composite.

\subsubsection{Compounding and Mixing}

To produce the composite, the ratio of the HDPE to the groundnut shell particles were measured 90/10, 80/20, and 70/30 the measurement was carried out using an electronic digital weighing balance. The two-roll mill machine was warmed up for about one hour $(1 \mathrm{hr})$ at a temperature of $150^{\circ} \mathrm{C}$. The materials were compounded via melt mixing and compression moulding using two roll mill and a compression moulding machine at a temperature of $140{ }^{\circ} \mathrm{C}$ and a pressure of 5 psi to obtain a homogeneous mixture. The weight fraction of the reinforcement was varied from 0-30 $(0,10,20$, and 30$)$. The samples were cooled, after the composite was removed from the mould. The procedure was repeated for all composition of the filler (particle). The compression mould process was carried out at the NILEST Samara Zaria, Kaduna State, Nigeria.

\subsection{Mechanical Property Test \\ 2.3.1 Hardness Test}

The micro indentation measurements were carried out at room temperature using Shimadzu HMV-1, Japan micro hardness tester. The test measures the penetration of a specified indenter into the material with a load of $0.3 \mathrm{kgf}$ that has a maximum hardness value of $100 \mathrm{HV}$ and a minimum hardness value of $010 \mathrm{HV}$. It consists of an indenter, a graduated circular tube and a flat surface which the sample to be tested was mounted. The sample was placed on the flat surface and a load was applied on the surface of the specimen to obtain the hardness value. The measurements were performed in accordance with ASTM standard E384 for micro-indentation hardness of materials [22]. The micro hardness was computed at five different locations for each value of load for the prepared samples where the average Vickers micro hardness number was calculated and recorded. 


\subsubsection{Tensile Strength Test}

The tensile testing machine used is the tensometer type W (with flexural fixture), Monsanto tensometer, UK. The testing of the samples was conducted at the Department of Metallurgical and Materials Engineering, Ahmadu Bello University, Zaria, Kaduna State, Nigeria in accordance with ASTM D638 standards. The samples were machined to dumbbell shape and then placed in the universal tensile testing machine. The test was determined using tensile machine by gripping the ends of a suitable prepared standard test sample, and then applying a continually increasing uniaxial load until the sample fractured. The tensile loads together with the corresponding extensions were recorded on the graph sheet for evaluation.

\subsubsection{Impact Energy Test}

Impact strength of a material is the capacity to absorb energy under shock or impact load. The impact test was conducted on the prepared GSP-HDPE composite on the treated samples using the charpy impact testing machine. The composite samples for the impact test were prepared according to ASTM D-256 with the dimensions of $55 \mathrm{~mm}$ (length) $\times 10 \mathrm{~mm}$ (width) $\times 10 \mathrm{~mm}$ (height) and also provided the $\mathrm{V}$-notch at the middle of the samples. The pendulum was raised to the test height and held there. The sample was mounted in the machine and the door of the machine was closed. The pointer for reading the impact energy value on the calibrated scale was adjusted to zero before the pendulum was released by means of a handle on the door of the machine. The pendulum falls from the height, breaking the sample and hitting the pointer to the test energy value. This process was repeated for all the samples, till all the impact test value for all the different composition was recorded and the average value was recorded.

\subsection{Water Absorption Test}

Water absorption test was used to determine the water absorption capacity of the synthesized composite under some specified conditions. The test was carried out by immersion of the samples in water bath at room temperature for a time duration. The samples were cut to dimensions $20 \times 20 \mathrm{~mm}$, the initial weight of the samples was taken with aid of an electronic digital weighing balance with tolerance of $0.001 \mathrm{~g}$. Then each of the samples were immersed in a beaker containing water and the new weight of the samples was recorded. The samples were immersed in water for a duration of $1-3 \mathrm{hrs}$, after immersion the surface of the specimen were cleaned dry and weighed immediately to measure their weight. The initial weight of samples is taken as $w_{1}$ and after the sample is removed from the water is taken as $w_{2}$. The percentage water absorption was obtained from the relationship in equation 1.

\section{RESULTS AND DISCUSSIONS}

\subsection{Groundnut Shell and Developed HDPE-CSP Composite}

Fig. 1(a-c) show the groundnut shell in the as received, untreated and treated conditions. The untreated groundnut shell is bright compared to the treated groundnut which is dark due to the removal of some elements during the treatment process. Fig. 1(d) shows the developed HDPE-GSP composite before conducting the various testing to ascertain the properties analysis.

$$
\% \text { Moisture Absorbtion }=\frac{W_{2}-W_{1}}{W_{1}} \times 100
$$
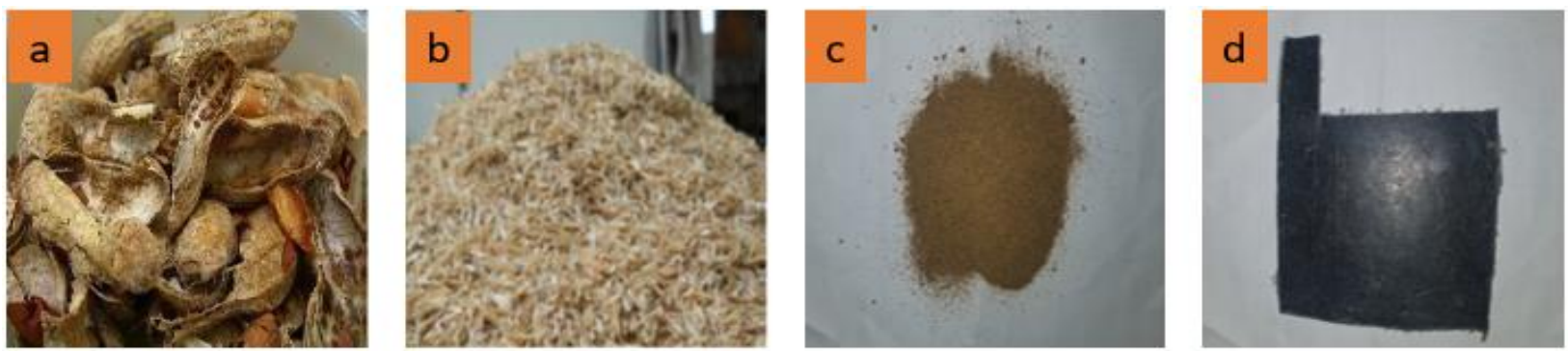

Figure 1: Groundnut shell (a) as received, (b) untreated, (c) treated and (d) Sectioned portion of developed HDPEGSP composite

\subsection{Mechanical Properties Analysis}

\subsubsection{Hardness Test}

Figure 2 explains the comparative analysis of the HDPE (control sample) and the GSP-HDPE composite subjected to alkaline treatment at various time intervals ranging from 1 to 3 hours. The unreinforced HDPE shows the lowest hardness value of $22.3 \mathrm{Hv}$. The GSP-HDPE reveals a progressive increase in hardness value as the wt\% of GSP increases from $10 \mathrm{wt} \%$ to $30 \mathrm{wt} \%$ for $1 \mathrm{hr}$ alkaline treatment. However, the hardness value for the $2 \mathrm{hrs}$ and $3 \mathrm{hrs}$ treated GSP-HDPE composite exhibited similar trend where there is a drop in hardness value from 71.73 to $54.2 \mathrm{Hv}$ and 42.87 to $34 \mathrm{Hv}$ for the $20 \mathrm{wt} \%$ GSP-HDPE composite. 
The $30 \mathrm{wt} \%$ GSP-HDPE composite exhibited a remarkable rise in the hardness value for both 2 hrs and 3 hrs treated composite from 54.2 to $76.13 \mathrm{Hv}$ and 34 to $67.9 \mathrm{Hv}$, respectively. The reason for the drop in hardness value for the 20 wt\% GSP-HDPE composite maybe ascribed to the poor interfacial bonding or poor adhesion of the reinforced GSP and HDPE. The increase in hardness is attributed to the strengthening effect of the GSP incorporated into the HDPE matrix.

\subsubsection{Tensile Test}

The tensile strength of the GSP-HDPE composite was found to decrease progressively as the percentage of GSP increased from $10 w t \%$ to $30 w t \%$ as shown in figure 3. However, the $10 w t \%$ reinforced CSP-HDPE treated for 3 hrs showed better tensile strength when compared to 20 and $30 \mathrm{wt} \%$ treated composites. The increase in wt $\%$ of the GSP is expected to increase the tensile strength but this trend may have resulted due to poor wettability and adhesion with uneven dispersion between the GSP and HDPE. Although, similar behaviour was previously reported in the use of coir fibre as filler reinforcement [16].

\subsubsection{Impact Energy Test}

The impact strength of treated GSP-HDPE composite attained maximum at $20 \mathrm{wt} \%$ GSP treated for $1 \mathrm{hr}$ as shown in Figure 4. However, the $10 \mathrm{wt} \%$ and $30 \mathrm{wt} \%$ treated GSP-HDPE composite recorded poor impact strength for all time conditions considered. The impact strength of the composite reduced after $20 \mathrm{wt} \%$ may be due to the reduction of elasticity of the material due to GSP addition thereby reducing the deformability of the HDPE. Moreover, considerable amount of energy absorption takes place through particle pull out process but after alkali treatment a strong mechanical interlocking develops between the GSP and HDPE and particle pull out is reduced which in turn decreases the impact strength.

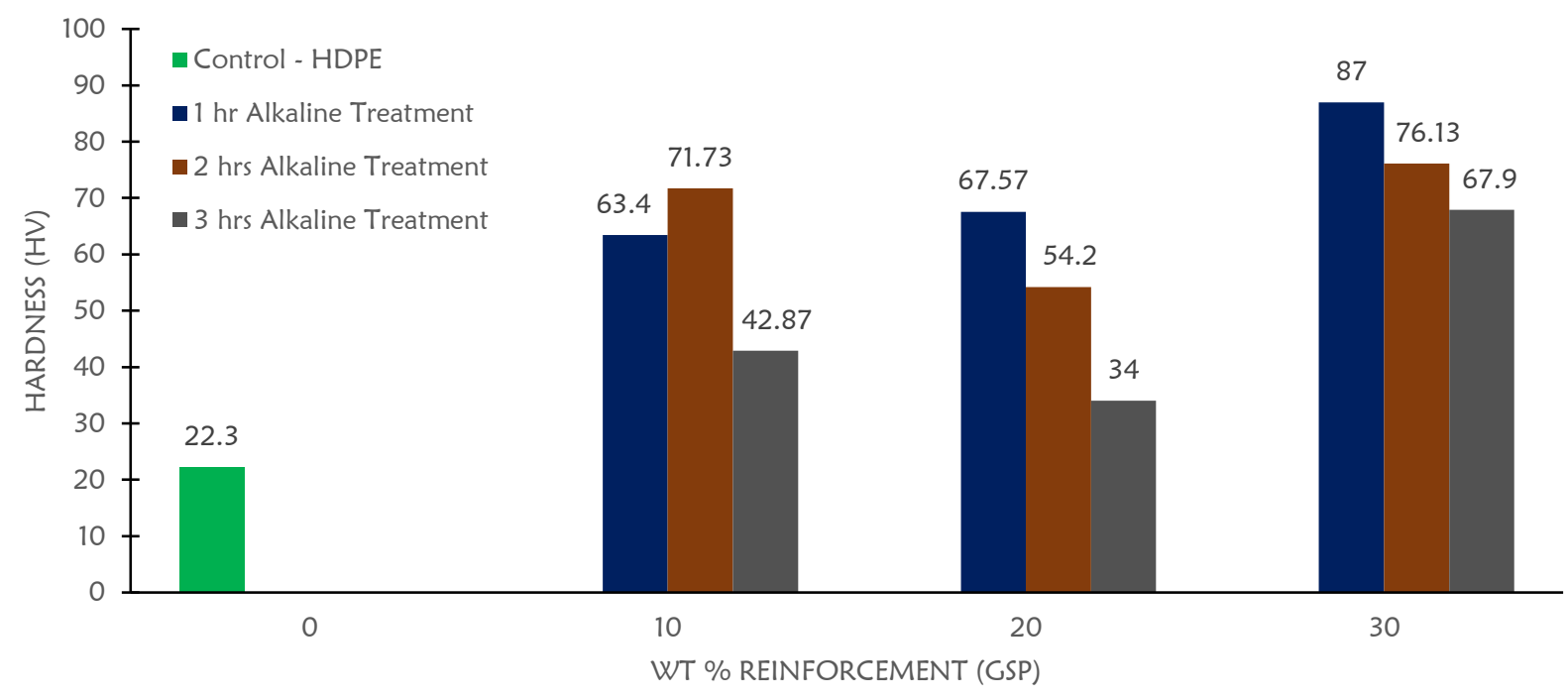

Figure 2: Effect of wt $\%$ GSP and alkaline treatment on hardness value of GSP-HDPE composites 


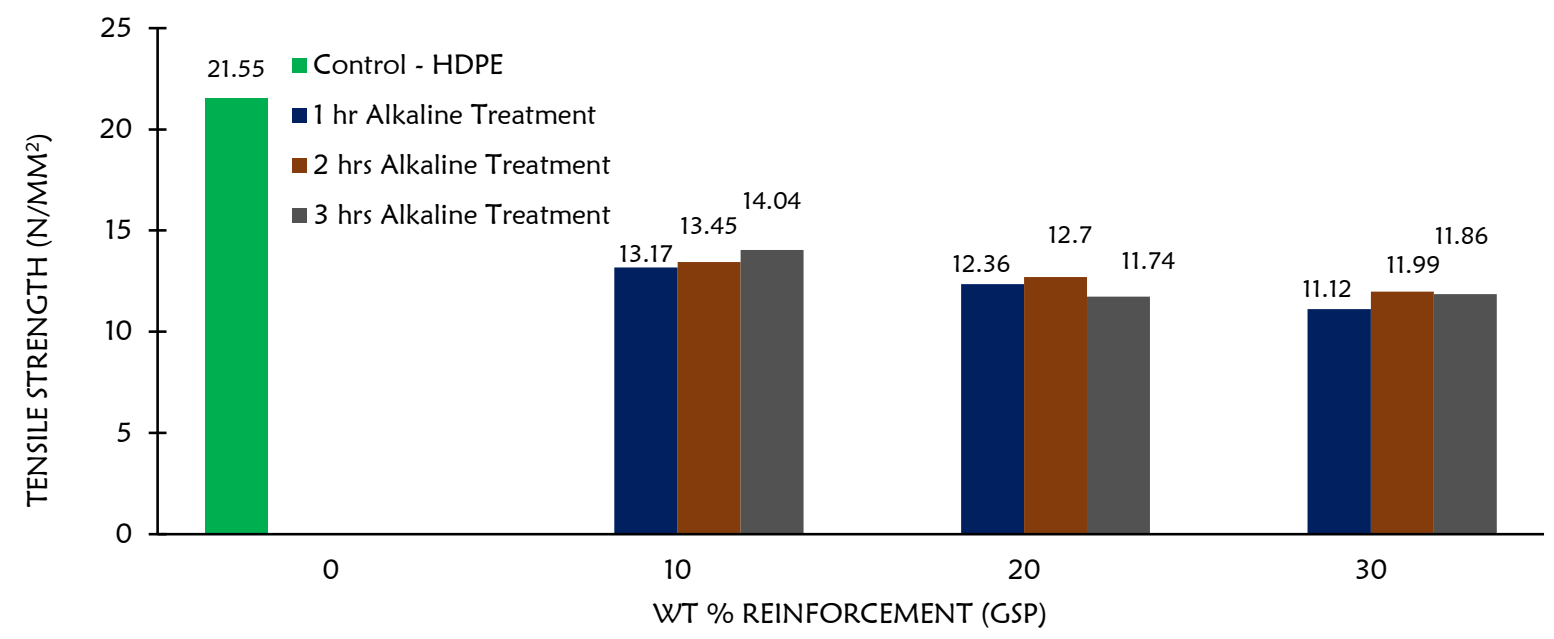

Figure 3: Effect of wt\% GSP and alkaline treatment on tensile strength of GSP-HDPE composites

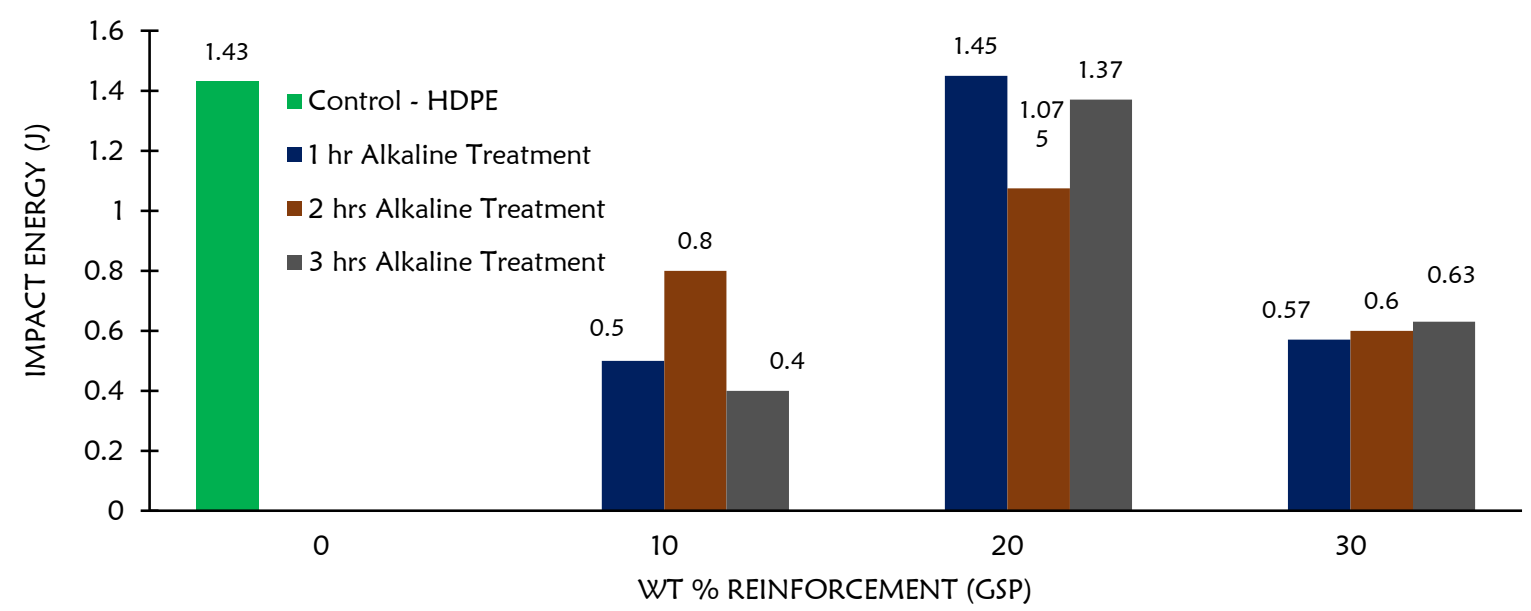

Figure 4: Effect of wt\% GSP and alkaline treatment on impact energy of GSP-HDPE composites

\subsection{Water Absorption}

The result obtained from water absorption test is plotted against the wt\% of GSP as shown in Figure 5. The water absorption rate attained maximum with $30 \mathrm{wt} \%$ CSP-HDPE treated for $2 \mathrm{hrs}$. When compared to the HDPE sample, the absorption value increased from $0.653 \%$ to $9.579 \%$. Similar trend of result was achieved by Munoz and Garcia (17) in their study. The increase in water absorption upon addition of wt\% GSP is as a result of the hydrophilic nature of groundnut shell which absorbs water, thereby creating room inside the composite resulting in micro-cracks that develop between the interface of the particle and the matrix giving rise to higher water absorption. 


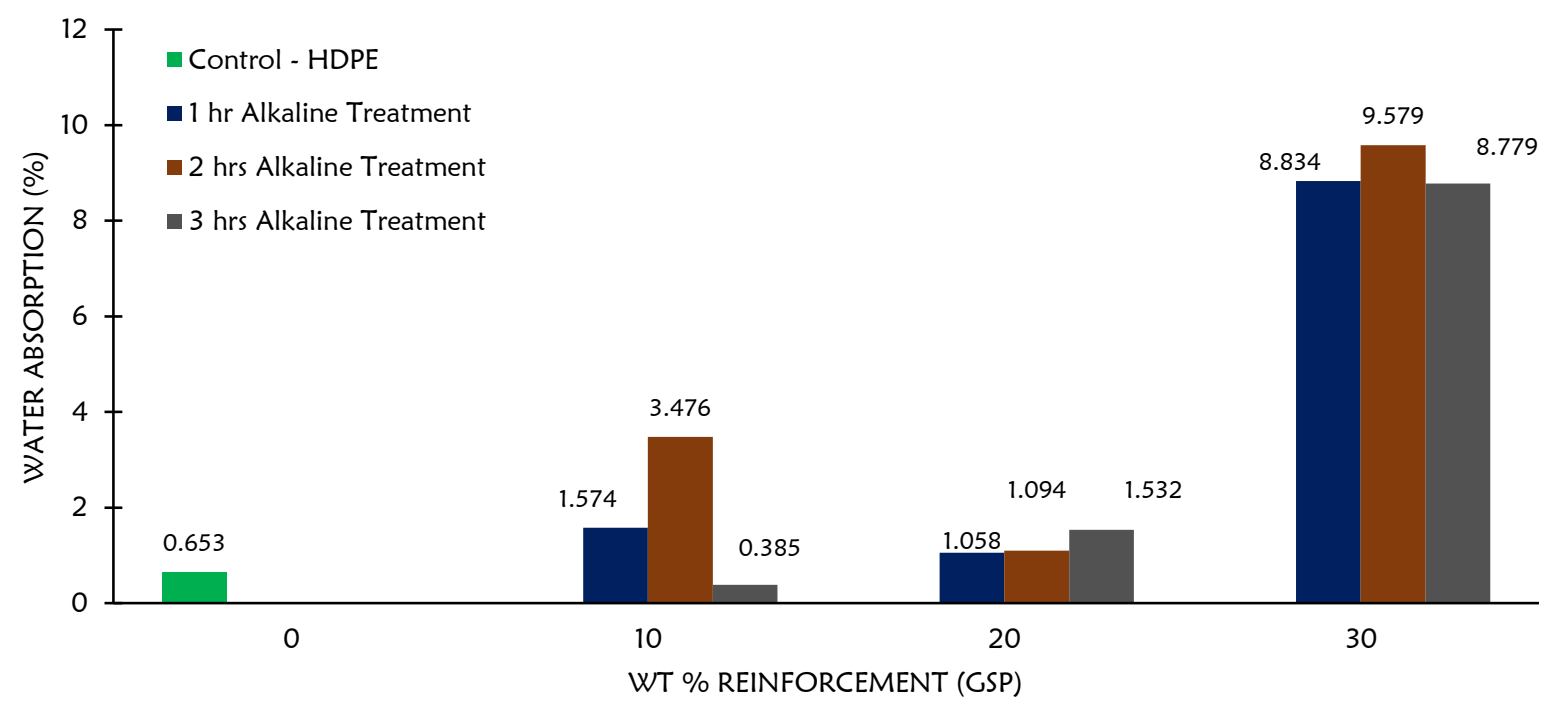

Figure 5: Effect of wt\% GSP and alkaline treatment on water absorption of GSP-HDPE composites

\section{CONCLUSIONS}

In this study, effects of wt\% GSP and alkaline treatment on the mechanical properties and water absorption behaviour of GSP-HDPE composite were reported. It was found that both the wt $\%$ GSP and alkaline treatment influences the properties of the composite. The following conclusion were drawn from the study;

1. The GSP-HDPE composite was successfully developed using the melt mixing and compression moulding technique.

2. The hardness value of the GSP-HDPE composite shows a steady rise as the wt\% GSP increases from 10-30 wt $\%$ for the $1 \mathrm{hr}$ treated CSP. However, the $2 \mathrm{hrs}$ and $3 \mathrm{hrs}$ treated GSP experiences a decline for the 20 $w t \%$ GSP. The $30 \mathrm{wt} \%$ GSP attained the maximum for all treatment time with $87 \mathrm{Hv}$ as the highest value.

3. The tensile strength of the composite decreases progressively as the wt\% of the GSP increases from 10-30 $w t \%$. Although, the $10 \mathrm{wt} \%$ reinforced GSP-HDPE treated for $3 \mathrm{hrs}$ attained the maximum value at 14.04 $\mathrm{N} / \mathrm{mm}^{2}$.

4. GSP-HDPE composite achieved optimum impact energy at $20 \mathrm{wt} \%$ GSP treated for $1 \mathrm{hr}$. However, the 10 and $30 \mathrm{wt} \%$ recorded poor impact strength due to the reduction in the elasticity of the HDPE as a result of GSP addition.

5. Water absorption rate attained high value at $30 \mathrm{wt} \%$ GSP-HDPE composite for all treatment time. However, the composite treated for 2 hrs achieved the maximum water absorption rate.

6. It is concluded that the $w t \%$ and alkaline treatment play a major role in the mechanical and water absorption properties of GSP-HDPE composite. However, an optimization analysis study will be required to fully achieve the best wt\% composite of GSP and alkaline treatment time.

\section{ACKNOWLEDGEMENT}

The authors acknowledge the support received from the Department of Metallurgical and Materials Engineering, Ahmadu Bello University, Zaria throughout the conduct of the research. Sincere appreciations are also extended to the technical team in the Departmental workshop where the experimental studies reported here were conducted.

\section{REFERENCES}

1. Mohanty, A. K., Misra, M. \& Drzal, L. T. (2002). Sustainable biocomposites from renewable resources: opportunities and challenges in the green material world. Journal of Polymers and the Environment, 10, 19-26.

2. Singh, A. A., Biswas, K., Priyanka, D., \& Palsule, S. (2014). Coconut fibre reinforced high density polyethylene composite by compatibilizer process. Applied Polymer Composite, 2(3), 167.

3. Adeniyi, A. G., Onifade, D. V., Ighalo, J. O. \& Adeoye, A. S. (2019). A review of coir fiber reinforced polymer composites. Composites Part B: Engineering, 176, 107305.

4. Teuber, L., Militz, H. and Krause, A. (2016) Processing of wood plastic composites: The influence of feeding rate method and polymer melt rate on particle degradation. Journal of Applied Polymer Science, 133, 43231.

5. Ismail, M. R., Yassene, A. M. \& Afify, M. S. (2011). Mechanical properties of rice straw fiber-reinforced polymer composites. Fibers and Composites, 12(5), 648-656. 
6. Favano, S. L., Ganzerli, T. A., De Carvalho Neto, A. G. V., Da Silva, O. R. R. F. \& Radovanovic, E. (2010). Chemical, morphological and mechanical analysis of sisal fiber-reinforced recycled high-density polyethylene composites. eXPRESS Polymer Letters, 4, 465-473.

7. Fang, H., Zhang, Y., Deng, J. \& Rodrigue, D. (2013). Effect of fiber treatment on the water absorption and mechanical properties of hemp fiber/polyethylene composite. Journal of Applied Polymer Science, 127, 942949.

8. Bledzki, A. K., Franciszczak, P., Osman, Z. \& Elbadawi, M. (2015) Polypropylene biocomposites reinforced with softwood, abaca, jute, and kenaf fibers. Industrial Crops and Products, 70, 91-99.

9. Arumugam, S., Kandasamy, J., Hameed Sultan, M. T., Md Shah, A. U. \& Nur Azrie Safri, S. (2021). Investigations on fatigue analysis and biomimetic mineralization of glass fiber/sisal fiber/chitosan reinforced hybrid polymer sandwich composites. Journal of Materials Research and Technology, 10, 512-525.

10. Adeosun, S. O., Taiwo, O., Akpan, E. I., Gbenebor, O. P., Gbagba, S., Olaleye, S. (2016). Mechanical characteristics of groundnut shell particle reinforced polactide nano fibre. Matéria (Rio de Janeiro), 21(2), 482 491.

11. Klyosov, A. A (2007). Wood-Plastic Composite. John Wiley and Sons Inc., New Jersey, US.

12. Jacob, J., Mamza, P. A. P, Ahmad, A. S. \& Yaro, S. A. (2019). Mechanical and dynamic mechanical characteristics of groundnut shell powder filled recycled high-density polyethylene composites. Science World Journal, 14(1), 92-97.

13. Olaitan, A. J., Terhemen, A. E., King, G. D. \& Oluwatoyin, O. R. (2017). Comparative Assessment of mechanical properties of groundnut shell and ruce husk reinforced epoxy composite. American Journal of Mechanical Engineering, 5(3), 76-86.

14. Musa, E. T., Hamza, A., Ahmad, A. S., Ishiuku, U. S. (2017). Investigation on the mechanical and morphological properties of high-density polyethylene (HDPE) leather waste composites. IORS Journal of Applied Chemistry, 10(1), 48-58.

15. Souza, P. S., Rodrigues, E. F., Preta, J. M. C., Goulart, S. A. S., Mulinari, D. R. (2011). Mechanical properties of HDPE/Textile fibers composites. Procedia Engineering, 10, 2040-2045.

16. Ng, Y. R., Shahid, S. N. A. M. \& Nordin, N. I. A. A. (2017). The effect of alkali treatment on tensile properties of coir/polypropylene biocomposites. IOP Conf. Series: Materials Science and Engineering, 368, 012048.

17. Munoz, E. \& Garcia-Manrique, (2015). Water absorption behaviour and its effect on the mechanical properties of flax fibre reinforced bioepoxy composite. International Journal of Polymer Science, 10, 390275. 